\title{
Health inequalities: new concerns about the children of single mothers
}

\author{
Ken Judge, Michaela Benzeval
}

\begin{abstract}
Objectives-To show that the exclusion from conventional class based analyses of child mortality of children whose parents are classified as "unoccupied" produces a misleading picture of health inequalities.
\end{abstract}

Design-Reanalysis of data published in the childhood supplement of the registrar general's decennial supplement on occupational mortality in England and Wales, which compares numerator data for registrations of deaths in children over the age of 1 but below their 16th birthday in 1979, 1980, 1982, and 1983 with data about children aged 1-15 who were enumerated at the 1981 census.

Results-Parents who are classified as "unoccupied" largely consist of economically inactive single mothers. Their children are estimated to represent $89 \%$ of the 614000 aged 1-15 classified as "unoccupied" in the childhood supplement. They have the worst mortality record of all social groups-an age specific death rate of $68 \cdot 8 / 100000$ a year, $42 \%$ worse than in social class $V(48 \cdot 4 / 100000)$ and worse than that of social class I $(22 \cdot 8)$ by a factor of 3 . At older ages (10-15 years) these children have a relative risk of death of $4 \cdot 14$ relative to classes I and II; the risk is 2.58 in children $0-4$ and 2.56 in those 5-9. Relative risks of child mortality in social classes $I$ and II in comparison to classes IV and V suggests a progressive shallowing from 2.08 at ages $1-4$ to 1.37 at ages 10-15. When unoccupied parents were combined with classes IV and $V$ and compared with classes $I$ and II, however, inequalities seemed to be pervasive throughout childhood; the relative risks were $2 \cdot 21$ for those aged 1-4 and 1.98 for those aged 10-15.

Conclusion-Children classified as unoccupied are almost certainly living in poverty as well as experiencing relatively high risks of mortality. Class based analyses which exclude them therefore produce a misleading picture of inequalities in child health. The implications for health policy are profound. Strategies to promote the nation's health should acknowledge the importance of material and social deprivation more explicitly.

\section{Introduction}

One of the main criticisms of The Health of the Nation is that it fails to pay serious attention to health inequalities. The white paper acknowledges "variations in health status between different socioeconomic groups" and recognises the "complex interplay ... of factors" which impact on health. ${ }^{1}$ But it emphasises the significance of differences in relation to individual risk behaviour rather than the poverty and disadvantage of the most vulnerable sections of the community.

One of the reasons why the government seems able to sidestep a real assault on health inequalities is its belief that many observed differences in health status cannot "be fully accounted for by ... factors such as socioeconomic groupings." Further research, therefore, is required "to elucidate the reasons for these differences." We aimed to respond to this challenge by showing how significant social trends-which are not captured by conventional social classifications, but which are exacerbating health inequalities-help to account for very substantial differences between population groups in rates of childhood mortality.

Reanalysis of childhood mortality data first published in 1988 raises new concerns about the health and circumstances of one of the fastest growing and most disadvantaged groups in society: lone mothers with dependent children who are largely reliant on social security benefits. The latest estimates suggest that more than one million dependent children are in such families. ${ }^{23}$ The specific objective of this paper is to show that these children have the worst mortality record of any social group.

The failure to pay more attention to what we believe is an increasingly serious health problem is a product of the way in which occupational mortality data are recorded and analysed. The over-reliance on occupational class, which is widely acknowledged to be of diminishing utility in stratifying many social groups, ${ }^{45}$ has falsely persuaded some commentators that inequalities in mortality are shallower among adolescents than at any other stage in the life cycle. ${ }^{\circ}$ In contrast, we argue that when data on mortality in all children are taken into account, inequalities associated with socioeconomic status are pervasive throughout childhood.

\section{Method}

OCCUPATIONAL MORTALITY

The decennial supplements of occupational mortality published by the Office of Population Censuses and Surveys are an important source of data about health inequalities. It is surprising, therefore, that greater use has not been made of the childhood supplement, which was published in 1988.

One of the supplement's most important findings is that class related differences in childhood death rates can be found in every age group for both sexes. Table I shows the number of children, the observed number of deaths, and age specific death rates for the different groups that are separately identified in the childhood supplement. Age specific death rates do not differ much between the non-manual social classes. However, the manual rates are greater than the non-manual ones and they show a much clearer class gradient. Such data, therefore, represent clear evidence of health inequalities among children aged 1-15. But they may underestimate the true extent of inequalities, since a large group of children-who at many ages have a particularly poor mortality record-are excluded from the main analyses. 
This excluded group, which the supplement categorises as "inadequately described" or "unoccupied," and which consisted of approximately 849000 children in 1981, is reported to have a variable pattern of death rates. The supplement states that "sometimes the rates are higher than for social classes IV and V and sometimes lower, irrespective of whether or not a social class gradient exists across the rest of the classes. Little attention has consequently been paid to this category in this report."

It is unhelpful-and possibly disingenuous-to lump together the categories "inadequately described" and "unoccupied" because-as Table I illustratestheir mortality records are very different. The group classified as inadequately described has an exceptionally good record, but the unoccupied group has by far the worst mortality record of any social group.

The term unoccupied is used as a residual term by the Office of Population Censuses and Surveys to describe people for whom an occupation cannot be stated. ${ }^{8}$ Relatively little is known about such people, although in oral evidence to the House of Commons Health Committee the head of medical statistics at the Office of Population Censuses and Surveys remarked that "one of the things that people are now suggesting about that other group who do not have an occupation is that they are forming ... an under class."

Whatever its precise definition, the unoccupied group accounted for $6 \%$ of all children $(61445)$-more than in either social class I or V-yet $14 \%$ of observed deaths (1690) occurred in this group. Its mortality record is not only worse than that of social class I by a factor of 3 but it is $42 \%$ worse than that of social class $V$ (table I).

Table II contrasts the main causes of death for children whose parents are classified as unoccupied with those whose parents had an occupation. Accidents and external causes of injury among the children of the subgroup of unoccupied families account for nearly

TABLE I-Childhood mortality (ages 1-15) in England and Wales in 1979, 1980, 1982, and 1983

\begin{tabular}{|c|c|c|c|}
\hline Classification & $\begin{array}{l}\text { No (\%) of children } \\
(1981)\end{array}$ & $\begin{array}{c}\text { No }(\%) \text { of deaths } \\
(1979-80 \text { and } 1982-3)\end{array}$ & $\begin{array}{c}\text { Age specific } \\
\text { death rate } \\
\text { (per } 100000 / \\
\text { year) }\end{array}$ \\
\hline \multicolumn{4}{|l|}{ Social class: } \\
\hline I & $57541(5 \cdot 7)$ & $524(4 \cdot 4)$ & $22 \cdot 8$ \\
\hline II & $224248(22.0)$ & $1926(16.0)$ & 21.5 \\
\hline III Non-manual & $98177(9 \cdot 6)$ & $913(7 \cdot 6)$ & $23 \cdot 2$ \\
\hline III Manual & $344861(33.9)$ & $3872(32 \cdot 2)$ & $28 \cdot 1$ \\
\hline IV & $145394(14 \cdot 3)$ & $1898(15 \cdot 8)$ & $32 \cdot 6$ \\
\hline $\mathrm{V}$ & $48622(4.8)$ & $941(7 \cdot 8)$ & $48 \cdot 4$ \\
\hline Armed forces & $13633(1 \cdot 3)$ & $155(1 \cdot 3)$ & $28 \cdot 4$ \\
\hline Inadequately described & $23458(2 \cdot 3)$ & $124(1 \cdot 0)$ & $13 \cdot 2$ \\
\hline "Unoccupied" & $61445(6 \cdot 0)$ & $1690(14 \cdot 0)$ & $68 \cdot 8$ \\
\hline Total & $1017379(100 \cdot 0)$ & $12043(100 \cdot 0)$ & $29 \cdot 6$ \\
\hline
\end{tabular}

$\star^{\star} 10 \%$ sample, 1981 census.

TABLE II-Causes of death for children under 15 in 1979, 1980, 1982, 1983

\begin{tabular}{|c|c|c|}
\hline \multirow[b]{2}{*}{ Cause of death } & \multicolumn{2}{|c|}{ No (\%) of deaths } \\
\hline & $\begin{array}{l}\text { All occupied } \\
\text { social classes }\end{array}$ & $\begin{array}{l}\text { Unoccupied } \\
\text { group }\end{array}$ \\
\hline Malignant neoplasms & $1785(17 \cdot 2)$ & $133(7.9)$ \\
\hline $\begin{array}{l}\text { Diseases of nervous system and sense } \\
\text { organs }\end{array}$ & ) & $100(6)$ \\
\hline $\begin{array}{l}\text { Organs } \\
\text { Diseases of respiratory system }\end{array}$ & $1096(10 \cdot 6)$ & $115(6.8)$ \\
\hline Congenital abnormalities & $1339(12.9)$ & $130(7 \cdot 7)$ \\
\hline $\begin{array}{l}\text { External causes of injury (including } \\
\text { poisoning) }\end{array}$ & $3082(29 \cdot 8)$ & $983(58 \cdot 2)$ \\
\hline Collision with pedestrian & $1024(9.9)$ & $276(16 \cdot 3)$ \\
\hline Other & $543(5 \cdot 2)$ & $155(9 \cdot 2)$ \\
\hline Submersion, suffocation, etc & $484(4 \cdot 7)$ & $159(9 \cdot 4)$ \\
\hline Other & $1031(10 \cdot 0)$ & $393(23 \cdot 3)$ \\
\hline Other causes & $2147(20 \cdot 7)$ & $221(13 \cdot 1)$ \\
\hline Total & $10353(100 \cdot 0)$ & $1690(100 \cdot 0)$ \\
\hline
\end{tabular}

^Including inadequately described.
$60 \%$ of deaths, twice the proportion in the rest of the population.

\section{IDENTIFYING "UNOCCUPIED" CHILDREN}

The main reason given by the Office of Population Censuses and Surveys for not making more of the data about the unoccupied group is related to the way in which child mortality is calculated. Numerator data are based on registration returns about child deaths, whereas denominator data are obtained from the 1981 census. In the vast majority of cases the occupational classification used in the census and at death registration is the same, but the term unoccupied might be interpreted differently. In practice, we do not believe this to be sufficiently important to invalidate comparisons. We argue that lone mothers constitute the vast majority of those classified as unoccupied at both census and death registration.

At death registration, registrars are instructed to make every effort to find out about the previous work experience of people, including those who might be unemployed or sick. But until changes in the registration of women's occupation were introduced in 1986 there was a major difference between men and women: "At the registration of the death of a child ... the instructions to the registrars specify that the occupation ... of a woman should not be recorded unless she has been in employment for most of her adult life." Bradshaw and Miller's work has shown that a substantial proportion of single mothers have never been in full time employment. ${ }^{3} \mathrm{~A}$ reasonable assumption to make on the basis of the instructions given to registrars before 1986, therefore, is that most of the deaths of children classified as unoccupied will have been registered by economically inactive lone mothers.

In a small number of cases, however, a woman without an occupation may be registering the simultaneous death of her spouse and child as the result of an accident. Although such women may be registered as unoccupied, they were not in fact lone mothers. The number of deaths for which this is likely to be true is so small that it ought not to affect the analysis presented here.

There can be little doubt that economically inactive lone mothers would have been classified as unoccupied in the census, but so might other people. It is important to establish, therefore, whether or not it is reasonable to suppose that the children of lone mothers represent a significant proportion of the unoccupied group recorded in the census. If it can be shown that most children recorded as unoccupied in the census also had economically inactive lone mothers then it would be reasonable to assume that the concerns about numerator-denominator bias expressed by the Office of Population Censuses and Surveys may be exaggerated.

The childhood supplement does not provide detailed information about the economic or household characteristics of the 61445 children classified as unoccupied on the basis of information from a $10 \%$ sample of the 1981 census. An examination of other reports based on the 1981 census, however, clearly shows that an overwhelming number of such children almost certainly belong to economically inactive, single parent families. ${ }^{20-13}$

Unfortunately, it is not a simple matter to estimate the number of children in such families. Nevertheless, the calculations set out in the box suggest that the number of children under the age of 16 living with lone mothers in 1981 and largely or totally dependent on state benefits was about 544000 in England and Wales. Comparing this figure with the estimate of 614450 derived from the childhood supplement implies that nearly $90 \%$ of the unoccupied children are in the most disadvantaged group of one parent families. 
The clearest supporting evidence that lone mothers would be classified as unoccupied at census and death registration comes from a very detailed survey of lone parent families in Britain by Bradshaw and Millar. ${ }^{3}$ This study found that $73 \%$ of lone mothers depended on income support at the time of the survey, and of these only $28 \%$ had had regular full time employment before becoming a lone parent. This implies that at least $53 \%$ of lone mothers would be classified as unoccupied; they would have been regarded as economically inactive at the census, and at death registration the instructions to registrars would preclude the recording of any occupational information.

For all practical purposes, it is reasonable to assume that the children classified as unoccupied at the census were living in poverty in one parent families. We have also established that the instructions given to registrars would have meant that deaths of children classified as unoccupied are almost certainly associated with economically inactive lone mothers. Much of the apparent concern about numerator-denominator bias, therefore, evaporates.

\section{Results}

In the light of these deductions the child mortality records of different age and social groups can be considered in more detail. Using social classes I and II combined as the reference point, Table III sets out the relative risks of child mortality for different social groups in three age bands: $1-4,5-9$, and $10-15$ years. It shows that the relative risks of mortality for children in social classes IV and V were higher than for those in classes I and II for all age groups, although the difference was not statistically significant at ages 10-15. Also, the relative risks of mortality for all age groups were highest among children classed as unoccupied. The confidence intervals show that the relative risks

How many children under 16 lived in families with an economically inactive lone mother?

To estimate how many economically inactive lone mothers there were in 1981, with children aged 1-15, in England and Wales, we have proceeded as follows:

(1) The number of one parent families in Great Britain in 1981 was estimated to be $850000 .^{10}$

(2) Ninety one per cent of one parent families were resident in England and Wales. ${ }^{11}$

(3) Eighty nine per cent of one parent families consisted of lone mothers. ${ }^{10}$

(4) The number of lone mothers in England and Wales in 1981 was estimated at 688000

(5) Haskey found, for $1987-9$, that $53 \%$ of lone mothers with at least one child under the age of 16 were economically inactive. ${ }^{2}$ We assume that this rate applied in 1981; thus there were 365000 such lone mothers.

(6) There were 1.58 children under the age of 16 for each economically inactive lone mother in $1981 .^{12}$

(7) Thus there were 577000 children under the age of 16 in families with an economically inactive lone mother in 1981.

(8) The percentage of children under the age of 16 normally resident in private households who had a reported age at last birthday of 0 on Census day in 1981 was $5 \cdot 75 .^{13}$

(9) Thus there were 544000 children aged 1-15 in families with an economically inactive lone mother in 1981 .

(10) The estimate in (9) can be compared with the 614000 children aged 1-15 classified as unoccupied in the childhood supplement occupational mortality.

(11) Thus, probably about $89 \%$ of the children classified as unoccupied are from families with an economically inactive lone mother.
TABLE III-Relative risk of child mortality ( $95 \%$ confidence interval) by social class and age, England and Wales, 1979, 1980, 1982, 1983

\begin{tabular}{lccc}
\hline & \multicolumn{3}{c}{ Age bands } \\
\cline { 2 - 4 } Social group & $1-4$ Years & 5-9 Years & $10-15$ Years \\
\hline I and II & 1.00 & 1.00 & 1.00 \\
& $(0.83$ to 1.21$)$ & $(0.80$ to $1 \cdot 25)$ & $(0.84$ to $1 \cdot 20)$ \\
IV and V & $2.08^{\star}$ & $1.71^{\star}$ & 1.37 \\
& $(1.75$ to $2 \cdot 49)$ & $(1.39$ to $2 \cdot 12)$ & $(1.14$ to 1.64$)$ \\
"Unoccupied" & $2.58^{\star}$ & $2.56^{\star}$ & $4 \cdot 14^{\star}$ \\
& $(2.07$ to $3 \cdot 22)$ & $(1.98$ to 3.30$)$ & $(3.43$ to 4.99$)$ \\
IV, V and unoccupied & $2 \cdot 21^{\star}$ & $1.93^{\star}$ & $1.98^{\star}$ \\
& $(1.88$ to 2.61$)$ & $(1.59$ to 2.35$)$ & $(1.69$ to 2.32$)$
\end{tabular}

${ }^{\star} \mathrm{p}<0 \cdot 05$.

among the unoccupied groups were always larger than for social classes I and II. In addition, they were at least as high as social classes IV and $V$ at ages 1-9 and significantly greater at age 10-15. Children aged 1-9 who were classified as unoccupied were $2 \cdot 6$ times as likely to die as those in social classes I and II, and the relative risk was in excess of $4 \cdot 0$ at ages $10-15$.

The broad picture that emerges from a consideration of mortality in social classes I and II and IV and V in table III seems to be consistent with the notion that inequalities become progressively shallower at older age groups. ${ }^{6}$ However, given the importance of the mortality record of the children of what we believe to be economically inactive, one parent families, any analysis of health inequalities will be seriously flawed if it fails to include this group.

When the unoccupied group-now largely identified as a particularly disadvantaged subgroup of one parent families - is added to social classes IV and V and the relative risk of the combined group is compared with that of classes I and II, a completely different picture emerges. Table III shows that in all three age groups, the risk of dying in the most disadvantaged group (classes IV and V plus the unoccupied) is consistently twice that of the highest group (classes I and II). One of the consequences of taking proper account of the mortality of children classed as unoccupied is to remove the misleading impression that inequalities decline during childhood. In fact, as this clearly illustrates, inequalities are relatively consistent throughout childhood. In particular, they are much more substantial at ages $10-15$ than is commonly supposed. ${ }^{\circ}$

\section{Discussion}

Our evidence suggests that a new approach to social stratification is required to assess health inequalities in childhood. It is clear that the worst child mortality is found among children classified as unoccupied, a term that is usually a euphemism for their economically inactive single parents.

The credibility of this contention is strengthened by a recent study of perinatal and infant mortality that linked vital registration data for deaths under 1 year so as to overcome numerator-denominator bias. One of the key findings was that for babies born outside marriage and registered by the mother alone-a total of $8 \%$ of all births in 1990 - the infant mortality rate was $13 \cdot 1$ (per 1000 live births), $80 \%$ higher than that of babies born within marriage. ${ }^{14}$ Furthermore, aggregated data from this source presented to the House of Commons Select Committee on Health show that in approximately two thirds of births registered solely by the mother she is classified as unoccupied. ${ }^{15}$

We believe that this evidence buttresses our conclusion that any failure to take account of children classified as unoccupied runs the very real risk of understating the extent of child health inequalities. This is especially the case when the unoccupied group is identified as largely consisting of single parent 
families dependent on state benefits, one of the fastest growing and most disadvantaged groups in society. By any stretch of the imagination, economically inactive lone parents as a group are at least as disadvantaged as those in social classes IV and V, who are commonly contrasted with their more privileged counterparts in classes I and II. There is a strong case, therefore, for comparing the combined mortality records of social classes I and II with IV and V plus the unoccupied to give the best aggregate picture of inequalities in child mortality.

If our analysis is valid, one consequence is that a greater proportion of observed health differences in childhood would be associated with socioeconomic variations in circumstances than can be accounted for by conventional social class groupings. Furthermore, an implicit corollary is that strategies to promote health should pay greater attention to financial hardship and other correlates of poverty than present policy seems inclined to do.

We must, however, acknowledge that the inferences on which the analysis in this paper are based are, of necessity, speculative. We believe that the assumptions we have made are reasonable and that the picture we paint is a valid one. Nevertheless, we have to concede that the evidence as it stands cannot be conclusive. Given that the implications are so profound, however, there is an urgent need to consider ways in which data from the 1991 census and vital registration can be linked in more illuminating ways so as to examine the phenomenon of the unoccupied in more depth
We are grateful for comments and advice from the health statistics division of the Office of Population Censuses and Surveys.

1 The Health of the Nation: A Strategy for Health in England. London: HMSO, 1992. (Cm 1986.)

2 Haskey J. Estimated numbers and demographic characteristics of one-parent families in Great Britain. Population Trends 1991;65:35-47.

3 Bradshaw J, Millar J. Lone parent families in the UK. London: HMSO, 1991. (Department of Social Security, Research Report No 6.)

4 British Medical Association. Deprivation and ill health. London: BMA, 1987

Whitehead M. Inequalities in health: the health divide. 2nd ed. London: Penguin, 1992

6 West P, Macintyre S, Annandale E, Hunt K. Social class and health in youth: findings from the west of Scotland twenty-07 study. Soc Sci Med 1990;30: 665-73.

7 Office of Population Censuses and Surveys. Occupational mortality childhood supplement. Registrar general's decennial supplement for England and Wales, supplement. Registrar general's decennial supplement for England

8 Office of Population Censuses and Surveys. Classification of Occupations, 1980. London: HMSO, 1980.

9 Dunnell K. Oral evidence, Wednesday 11 December 1991. In: House of Dunnell K. Oral evidence, Wednesday 11 December 1991. In: House of
Commons Health Committee. Second report. Maternity services. Vol 2. Minutes of evidence. (HC 29-II, Session 1991-92.) London: HMSO, 1992:S70-5

10 Haskey J. One-parent families in Great Britain. Population Trends 1986;45: 5-13.

11 Office of Population Censuses and Surveys. Census 1981, national report, Great Britain, part 2. London: HMSO, 1983.

12 Office of Population Censuses and Surveys. Census 1981, household and family composition, England and Wales. London: HMSO, 1984

13 Office of Population Censuses and Surveys. Census 1981, national report, Great Britain, part 1. London: HMSO, 1983.

14 Office of Population Censuses and Surveys. Mortality statistics: perinat and infant: social and biological factors. Review of the registrar general on deaths in infant: social and biological factors. Review of the registrar general on deat
England and Wales, 1990. London: HMSO, 1992. (Series DHS No 24.)

15 Alberman E. Memorandum to Health Committee. In: House of Commons Health Committee. Second report. Maternity Services. Vol 2. Minutes of evidence. (HC 29-II, Session 1991-92.) London: HMSO, 1992:S47-69

\title{
Epidemiology of Alzheimer's presenile dementia in Scotland, 1974-88
}

\author{
Gerard McGonigal, Brenda Thomas, Cecilia McQuade, John M Starr, William J MacLennan, \\ Lawrence J Whalley
}

\section{8.}

Abstract

Objective-To describe the epidemiology of presenile Alzheimer's disease in Scotland from 1974 to

Design-Retrospective review of hospital records

St Thomas's Hospital, Stockport

Gerard McGonigal, senior

registrar in geriatric medicine

Department of Mental

Health, University of

Aberdeen, Aberdeen AB9

2ZD

Brenda Thomas, research

assistant

Cecilia McQuade, research assistant

Lawrence J Whalley,

professor

Hammersmith Hospital, London

John M Starr, senior registrar

in geriatric medicine

University of Edinburgh, Edinburgh

William J MacLennan,

professor of geriatric medicine

Correspondence to:

Professor Whalley. psychiatric hospital with various diagnoses dementia. Diagnoses were classified by National Institute for Communicative Disorders and Stroke and Alzheimer's Disease and Related Disorders Association Criteria and the Hachinski score. Completeness of the study sample was evaluated by scrutiny of neurology outpatient and general hospital records.

Setting-All general psychiatric hospitals in Scotland.

Subjects-All patients with onset of dementia aged 40-64.

Main outcome measures-Probable and broad Alzheimer's disease, sex of patient, age at onset.

Results-5874 psychiatric hospital records, 129 neurology outpatient records, and 89 records from non-psychiatric hospitals were examined. 317 patients met criteria for probable Alzheimer's disease, 569 met criteria for broad Alzheimer's disease, and 267 met those for multi-infarct dementia. Minimal incidences per 100000 population aged 40-64 years were $22 \cdot 6(95 \%$ confidence interval, $20 \cdot 2$ to $25 \cdot 2)$ and $40.5(38.9$ to $42 \cdot 3)$ per 100000 for probable and broad Alzheimer's disease. In the 1981 census year the annual incidence of probable Alzheimer's disease was $1.6(1.0$ to $2 \cdot 6)$. Women were at greater risk with incidence rates for probable Alzheimer's disease of $28.2(24 \cdot 5$ to 32.4$)$ per 100000 compared with $16.5(13.8$ to 19.8$)$ per 100000 for men. The incidence per 100000 for multi-infarct dementia was greater in men $(25 \cdot 1,23 \cdot 3$ to $27 \cdot 1)$ than women $(13 \cdot 4,12 \cdot 1$ to $14 \cdot 8)$.

Conclusion-Female sex seems to be positively associated with development of Alzheimer's disease before age 65 years.

\section{Introduction}

Old people have the highest incidence of dementia, a condition with over 100 distinct causes.' Although Alzheimer's disease is the most important cause of illness. Most studies have investigated senile dementia in relatively small populations. ${ }^{34}$ Although fewer people develop presenile Alzheimer's disease, ${ }^{145}$ such patients are more likely to be known to the health service than older sufferers. ${ }^{6}$ Studies that use health service data to estimate the incidence and evaluate the natural course of presenile Alzheimer's disease may be considerably more accurate and informative than those of senile disease. ${ }^{7}$ Substantial progress has been reported in understanding the molecular pathology of presenile Alzheimer's disease ${ }^{8}$ but this cannot be extrapolated to senile forms before the epidemiology of presenile disease is known

Incidence of disease needs to be known for aetiological studies but is also important to those planning diagnostic services within the health service. ${ }^{9}$ For dementia, ${ }^{2}$ there are few epidemiological data on the 